\title{
The courts and child protection social work in England: tail wags dog?
}

\section{Abstract}

In England, the problem of excessive delay in court proceedings about children is long-standing, and there have been numerous initiatives over the years to tackle it. Under the Children and Families Act 2014 there is now a statutory limit of 26 weeks for care proceedings (with provision for longer where justified). If this is to be achieved, the quality of the work that local authorities undertake with children and families before proceedings are started will be more important than ever, and the courts will have to take due account of it. This paper draws on research into the formal 'preproceedings process' in England and Wales, to assess the prospects for the new approach. The research was undertaken in 2010-12, and involved a file survey, observation of pre-proceedings meetings, interviews with key participants (including social workers, lawyers and parents) and a group discussion with judges. The paper considers the implications of the new approach for relationships between the courts and local authorities, in particular how pre-proceedings work should be conducted. The danger is that pre-court practice may become less about family support, more about evidence and timescales, less about prevention of proceedings and more about preparation for court.

Keywords: care proceedings; social work and law; children and families; child safeguarding; prevention.

In England, the problem of delay in child protection and child care social work is well-known and much bemoaned - delay in addressing family difficulties and providing relevant services in the early stages, delay in bringing the 'hard cases' to court, delay during court proceedings, and yet more delay and uncertainty afterwards, in achieving a stable placement for the child (e.g. Davies and 
Ward, 2012; Family Justice Review, 2011a, b; Sinclair et al., 2007). In particular, there has been a strong tendency for the legal and social work sides to blame each other for the slowness and holdups. The courts see the hardest cases, and with the benefit of hindsight are likely to ask 'why wasn't this brought to court long ago?', especially in neglect cases. They may also be critical of social workers for poorly prepared evidence, and not keeping to court-directed deadlines for further assessments and reports. On the other hand, social workers and their managers are often critical of courts for disparaging social workers, discounting their evidence, and ordering new or repeat assessments by independent 'experts' as a matter of course. In the social work view, these often end up coming to the same conclusions that they had recommended at the start of the proceedings (Dickens, 2006). (The challenges of delay and tensions between the courts and welfare agencies are well-known in other countries too: for example, from the USA, see Courtney and Hook, 2012; Wattenberg et al., 2011.)

This pattern of mutual misunderstanding and recrimination was recognised by the Family Justice Review of 2010-11 (described further below) and this instigated a concerted drive to reduce the duration of care proceedings, with a statutory requirement that cases should normally be completed within 26 weeks (Ministry of Justice and Department for Education, 2012; Children and Families Act 2014, s.14). The key components are a reorganised court system, which prioritises judicial continuity; a higher test for ordering expert assessments (that they are 'necessary' rather than 'reasonably required': s.13 of the Children and Families Act 2014); and a new framework for the required documents, case allocation and timetabling. This is the new 'Public Law Outline' (Practice Direction 12A, 2014), an early version of which was implemented from summer 2013. The expectations are that the courts will take a more robust approach to case management (e.g. keeping a tighter grip on the timetable), and that local authority social workers will produce better focused statements and evidence (local authorities are the bodies that take care proceedings). There is new statutory guidance for local authorities on care proceedings and pre-proceedings work (Department for Education, 2014b). At the same time, there is also a strong programme from central government 
to get more children in care adopted more quickly. The Department for Education publishes 'adoption scorecards' on local authority performance in placing children in adoptive families (Department for Education, 2012, 2014a), and in 2012-13, almost 4,000 children were adopted from care, the highest figure since 1992 (Department for Education, 2013b).

There is no doubt that care proceedings have been afflicted by much unnecessary delay, and that children have suffered as a result of the uncertainty and the length of time before they reached a secure placement (whether that was with a parent, a relative, in long-term foster care or an adoptive home). Even so, courts and social work agencies alike face the same dilemma: can delay be reduced without undermining help to families, and without compromising fairness and thoroughness?

If proceedings are to be completed more swiftly, the work that local authorities undertake beforehand will need to be of a good enough standard and (most important, as we shall see) the courts will need to take due account of it. This paper presents findings from a study of the formal 'pre-proceedings process' in England and Wales (Masson et al., 2013), drawing on the research findings to assess the progress and prospects of the current policy and legal developments.

The pre-proceedings process was introduced in 2008 , as part of an earlier attempt to reduce the number and duration of care proceedings (Department for Children, Schools and Families, 2008; Welsh Assembly Government, 2008). It should be used when a local authority considers that there are grounds for starting care proceedings, but the case does not require immediate action. In these circumstances, the authority should send the parents a 'letter before proceedings', outlining their concerns and inviting them to a meeting to discuss these. The parents are entitled to a lawyer to attend the meeting with them. The process has the dual aim of trying to divert cases from court if possible, by helping to bring about improvements in parental care or identifying alternative care arrangements; or if not, to reduce delay in the subsequent proceedings by ensuring that all alternatives have been explored beforehand and the case is well prepared. 


\section{Background}

\section{The court context}

This paper focuses on developments in England, but there are overlaps and differences with the situation in Wales. The court system is the same for England and Wales, and the principal piece of legislation for child protection and child care proceedings, the Children Act 1989, applies in both countries. However, as devolution has developed in the United Kingdom since 1998, social care policy (for adults and children) has become increasingly separate. This means that whilst directives from the judiciary about care proceedings, such as the Public Law Outline, apply equally in the two countries, regulations and guidance to local authorities are issued in separate (but often parallel) versions (e.g. the 2008 statutory guidance on court orders, which introduced the formal preproceedings process: Department for Children, Schools and Families, 2008; Welsh Assembly Government, 2008).

Concern about delay in child care proceedings has been long-standing (e.g. Booth, 1996), and over the years there have been numerous reviews and procedural changes (e.g. Lord Chancellor's Department, 2002, 2003; Brophy, 2006; Department for Education and Skills et al., 2006; Judiciary for England and Wales, 2008). It should also be noted that concerns about financial cost, as well as children's well-being, are behind the drive to reduce the number and duration of court proceedings about children (e.g. Department for Constitutional Affairs, 2005).

For all the effort and exhortations, the number of care cases and the time taken to conclude them continued to increase over the first decade of the $21^{\text {st }}$ century. In the year April 2011 to March 2012, there were over 10,000 care applications in England involving a total of more than 17,000 children, a record number, $11 \%$ higher than the year before (Children and Family Court Advisory and Support Service, 2013) (Cafcass); and cases completing in the year ending June 2011 had taken, on average, 
56 weeks (Family Justice Review, 2011b: 5, 103-4). Cases taking more than two years were not uncommon (see Masson et al., 2008; Cassidy and Davey, 2011).

In 2010 the Labour government established a review of the family justice system. This was taken forward by the Conservative-Liberal Democrat coalition government after the general election of May 2010. The Family Justice Review published an interim report in March 2011 and a final report in November that year.

The Review identified the main causes of delay in care proceedings as being repeated chances for the parents to make the required changes, and extra assessments (Family Justice Review, 2011a, b). It considered there were two major factors behind this: a culture of mistrust between local authorities and the courts, and intense awareness, from all sides, of the seriousness of the decisions to be made. Together, these led to routine commissioning of new assessments, duplication of work and 'a vicious cycle of inefficiency and delay' (Family Justice Review, 2011a: 101). The Review proposed that the power to order further assessments should be restricted and there should be a statutory time limit of 26 weeks for all but exceptional cases. There were warnings from parents' advocacy groups, legal representatives and others that the time limit could lead to miscarriages of justice if the evidence was not tested thoroughly or options explored fully (e.g. Bar Council, 2012; The College of Social Work and the Family Rights Group, 2013; and see the discussion in House of Commons Justice Committee, 2012); but the proposal was accepted by the government (Ministry of Justice and Department for Education, 2012), and became law in sections 13-14 of the Children and Families Act 2014, which came into force in April 2014. Ahead of the legislation, in summer 2013, the courts adopted a pilot version of the new Public Law Outline, and started working towards the new deadline.

The local authority context: pre- and post-proceedings work 
It is important to remember that the cases which come to court are the 'tip of the iceberg' in terms of the full workload of local authority children's services departments. This includes family support and child protection work, and work with children and young people in care and after care.

In terms of work before proceedings, there are three inter-related dimensions. There is all the preventive work that local authorities and their partner agencies undertake, with cases of 'children in need' and 'children in need of protection', under sections 17 and 47 of the Children Act 1989. Usually this is effective, at least in the sense that most cases do not go to court. The last stage of preproceedings work is preparation for taking the case to court, such as completing necessary assessments, collating the evidence, and making the plan for the child's placement. In between, the formal pre-proceedings process may help to keep cases out of court, be a framework for the final preparations or more ambiguously, try to do some of both at the same time. One of the challenges of child and family social work is that, in 'edge of care' cases, the task is to offer support to a family and simultaneously gather and assess evidence for possible proceedings. In this sense, formal preproceedings work epitomises the care and control tensions that are so often at the heart of social work.

Local authorities have a duty to promote the upbringing of 'children in need' by their families, in so far as this is consistent with their welfare. They may provide, or arrange for the provision of, 'early help' services before a child reaches the s.17 threshold, but 'child in need' is the starting point for intervention by local authority children's social work services. On 31 March 2013, there were 382,400 children in need in England, a rate of 325.7 per 10,000 children (Department for Education, 2013a).

Some of these children will be considered children in need of protection. Here, a decision is made in an initial child protection case conference that the child is suffering or likely to suffer significant harm, but can be protected by being on a multi-agency child protection plan, rather than going to court (HM Government, 2013). There were just over 60,000 such conferences in England in 2012-13, 
and 52,700 children became subjects of child protection plans. At $41 \%$ of cases neglect is the most common category of concern (Department for Education, 2013a).

Then there are the children who are in care. There were 68,110 children in care on 31 March 2013. Just over 18,000 of these children were 'accommodated' under s.20 of the Children Act, which means there is a voluntary agreement with the parents and no court order (although it should be noted that the 'agreement' may not always feel very voluntary to the parent, or indeed to the child; and in some cases care proceedings may be underway but without an interim order). There were 11,540 children on interim care orders on that date, with care proceedings in process; and 28,640 on care orders. There were also 9,240 children on placement orders. This is an order that gives the local authority permission to place the child for adoption. Some of these children have been waiting a considerable time and now have very little chance of being adopted (hence the government policy to speed up the adoption process). Beyond these children are those who have been placed with kin or adopters, or who have left care as young adults, to whom the local authority owes duties to provide other support services.

This overview indicates that the cases in care proceedings, whilst undoubtedly a major part of the work of a local authority children's services department, and a notably demanding, time-consuming and expensive one, are only part of the story. Far more children need to be helped on either side of care proceedings - the children and families who receive family support services, those on child protection plans, those in care and who have left care.

The social work context: practice

The challenge facing social work with children and families in England is to respond to the high level of political and professional attention that is properly being given to reducing the duration of court proceedings and tackling delay throughout the system, without losing sight of core values and skills of effective practice with children and families. The frustrations about delay should not be allowed 
to eclipse the benefits of thoughtful, sustained work, the time needed to build relationships and trust, and the benefits of working with families to build up and on their own strengths and resources.

The pressure to speed things up interacts in complex ways with another policy and practice agenda, to improve preventive services and keep children at home safely. Government policy asserts the importance of programmes to tackle child poverty and disadvantage, and skilled 'early help' for families with additional difficulties (Department for Education, 2011, 2014b), but in the current climate of time limits and tightly restricted resources, there have been warnings that early intervention may be less supportive and more driven by 'an unforgiving approach to time and to parents' (Featherstone et al., 2013: 5). In an overview of 15 recent research studies on safeguarding children in England, Davies and Ward (2012) are clear on the dangers of over-optimistic assessments and repeated chances for parents to make the required changes, but also observe that services need to be offered for long enough to help families overcome problems that are often long-standing and deeply entrenched.

The requirement is for regular and rigorous review of the decision to continue supporting a family to care for their child at home, or whether separation is necessary because of immediate risk or because the changes cannot be made in the child's timescale (Brown and Ward, 2012; Ward et al., 2014). Not all time spent prior to proceedings is necessarily delay, but if cases do end up in court, hindsight makes it all too easy to criticise repeated attempts to work with the parents, losing sight of the pressures and priorities that shaped those decisions at the time.

\section{The research study: the pre-proceedings process}

As noted earlier, the formal pre-proceedings process was introduced in 2008. A study of the process was undertaken in 2010-12, by researchers from the universities of Bristol and East Anglia (Masson et al., 2013; see also Dickens et al., 2013; Masson and Dickens, 2013). It took place in six local 
authorities, and involved a case file study (207 cases), observation of meetings (36), and interviews with social workers (19), social work managers (16), local authority lawyers (16), private practice lawyers (19) and parents (24). There was also a focus group discussion with judges. Ethical approval was given by the two universities. Informed consent was given by all interviewees and participants in the observed meetings.

Despite the fact that the 2008 guidance required the use of pre-proceedings process in all nonimmediate cases, the national take-up never approached that level. There was no formal system for monitoring the use or effectiveness of the process, but an indication of its use is the number of legal aid bills paid to lawyers for advising parents in the process. In 2009-10 this was just under 6,300, falling to less than 4,000 in 2012-13 (Masson et al., 2013). (This is a rather imprecise guide: some parents may not have sought legal advice at all, in other cases both parents may each have had their own lawyer.)

The file study was a sample of cases that had started proceedings in 2009 , and cases which had entered the pre-proceedings process in the same period but not gone into care proceedings. In all there were 207 cases. Field researchers completed a detailed schedule on each of the cases. The pre-proceedings process was used in 120, and 87 went direct to court. Most of the children and their families entering the pre-proceedings process were well known to the local authority, and over $60 \%$ were the subject of a current child protection plan at the time it was started.

The process was not intended to divert the case from court in 23 cases, rather to inform the parents of the local authority's intention to start proceedings. That left 97 cases where there was a possibility of diversion. In these cases the parents would be asked to agree to a set of proposals from the local authority, typically involving requirements such as participation in further assessments, compliance with social work visiting, engaging with programmes to reduce drug or alcohol use, ensuring the child's attendance at the health centre, nursery or school, keeping the home in good 
condition, keeping the child away from others considered to be a risk to him/her, and in some cases agreeing to the child living with relatives.

Six months after the process was started two-thirds of those cases, 65 , had gone into care proceedings (two in new authorities, the families having moved). There were two families who returned to their home countries. Of the remaining 30 cases, the child/ren were in alternative care arrangements in ten, which includes living with the other parent or relatives, or accommodated with foster carers under s.20 of the Children Act. In the other 20 cases, parenting was considered to have improved sufficiently for the child/ren to remain at home.

The diversion rate from the 33 observed cases was considerably higher. One explanation is that these took place between autumn 2010 and January 2012, when local authorities had more experience of the process. Another is that the file sample includes cases where the parents were sent a letter but did not attend the meeting. Attendance is likely to indicate a higher degree of engagement and therefore a greater chance of diversion. Out of 28 meetings where diversion was a possibility, 19 had not entered care proceedings by the time of the follow-up enquiry, which was at least six months in all but two cases (Masson et al., 2013: 154-61). The child/ren were in alternative care arrangements in four of those cases.

The dangers of delay are apparent in two respects. The first concerns pre-court delay. The letter and the meeting, and the advice of their own lawyer, may help bring about improvements in parental care or cooperation, but there is a danger of short-lived change. Unless cases are monitored carefully for a sufficient period of time after the meeting social workers will not know if standards of care or cooperation have deteriorated, meaning yet more delay before action is finally taken. The point here is that diversion may not always be a good thing for the children.

The second aspect of delay concerns what happened at court. A major finding of the study was that use of the process made no significant difference to the duration of subsequent care proceedings. 
On average care cases that had been through the pre-proceedings process took 51 weeks to complete, whereas the 87 cases which had gone direct to court took on average only slightly (and not significantly) longer, 52.5 weeks (Masson et al., 2013: 172).

The courts did not seem to pay much, if any, regard to what had happened during the preproceedings period. Indeed, in the focus group with judges, one of them said '... it doesn't really figure in my mind generally speaking - it doesn't feature very much', and another 'The fact that we don't really notice it signals to me that it's just failed that purpose entirely'. Confirming this picture, a study of care proceedings cases starting in November 2011 found that in a third of the cases the children's guardian did not know whether or not a letter before proceedings had been sent (Cafcass, 2012).

For local authority interviewees, the court's failure to take account of the pre-proceedings process was a major disappointment and frustration, as shown in this quotation, from a local authority lawyer:

... the whole point as we understood it, was the judiciary would be a lot firmer on the number of assessments, particularly if we have done them before - because the whole point is to frontload it and to avoid all of that under care proceedings. In theory, care proceedings are meant to be shorter. But what we were finding was that even though we did assessments, and they were agreed by the parents with the letters of instruction, we would get into court and we were asked to re-do certain things ... we were almost back at square one. So maybe in certain cases, if we know we are likely to issue anyway, we might as well do it under care proceedings, we save six months.

The judges acknowledged that they had heard such complaints from other local authorities, not just the six in our study. They gave a number of explanations for not paying as much regard to preproceedings work as the authorities would like. One was that it was not brought to their attention by 
the local authority's representatives; they also blamed the poor quality of some social work reports, but more fundamentally, the judges had doubts about whether an assessment completed or commissioned by the local authority could truly be independent. They also said that the higher courts would overturn their decisions if they did not allow new assessments, and clearly felt pressured by the prospect of judicial disapproval; as one put it '... it's so much easier to, say, spend f5,000 doing another assessment and the appeal won't occur'.

\section{Discussion}

On the face of it there are fundamental tensions between speed and thoroughness in care proceedings, which have implications for pre-proceedings work. If a case is to be completed within the tight timescales, it must come to court as fully prepared as possible. Take up of the original preproceedings process declined because the courts did not recognise the work done in it, and therefore staff in the local authorities could see no benefit in using it, to them or the child. At the same time however, the courts cannot unquestioningly accept the pre-proceedings work that is put before them: even if the case is not contested they have to be satisfied that the grounds are met and the proposed order is in the child's interests; and if it is contested then they have to hear the alternative arguments. The introduction of the 26 week limit gives a new impetus for preproceedings work, and the number of legal aid bills paid for this work rose to just over 5,000 in 201314 (figures supplied to authors by the Legal Aid Agency), but also threatens to change the character of this work, making it more about preparation for court, and less about prevention.

\section{Achieving the 26 week limit}

Subsequent research has shown that the drive to reduce the duration of proceedings has had a marked impact, with widespread support from social work and legal practitioners. Average duration has been falling notably since early 2012, under the impetus of the Family Justice Review, enhanced by the early introduction of the new Public Law Outline and forceful encouragement from the 
President of the Family Division (the leading family judge in England and Wales). By the end of March 2014, the average (mean) duration was 32 weeks (median 26.3 weeks: Ministry of Justice, 2014: 15-16).

Two research studies, although both limited because of their early timing and relatively small size, have given positive pictures of the changes. The first was an evaluation of an initiative in three local authorities in London in 2012-13 to meet the 26 week goal ahead of the national moves in that direction. This was the 'Tri-borough care proceedings pilot' (Beckett et al., 2014). In the pilot year the median duration of care cases was 26.5 weeks, compared to 49 weeks the year before (note, this was achieved under the old Public Law Outline). The pattern of orders made in the pilot year was broadly similar to the pre-pilot year, and the proportion of cases ending in care and placement orders was exactly the same, suggesting that swifter proceedings had not distorted case outcomes. None of the practitioners interviewed for this study, which included lawyers who represent parents and Cafcass children's guardians, thought that there had been unfairness in any case in which they had been involved. A key observation was that thoroughness does not mean simply ordering more assessments, but rather thinking more clearly and robustly about the evidence that is already available, and keeping a sharp focus on the welfare of the child.

As regards pre-proceedings work, the notable finding was that there had been a tightening up here too. In the pre-pilot year, the median length of time in the formal pre-proceedings process for cases which went to court was 16 weeks, which fell to 9 weeks in the pilot year. But for new-born baby cases (where proceedings were commenced in the first week of the child's life) the median length of time from the letter to the issue of proceedings rose from 5 weeks to 8 weeks. Given that care proceedings cannot be started until the child is born, this suggests more proactive planning and decision-making in those cases (see also Masson and Dickens, 2014). However, use of the preproceedings process made no significant difference to the subsequent duration of care proceedings (this finding held in the pre-pilot and pilot years). 
The second study was an action research project to evaluate the early impact of the pilot Public Law Outline (Ipsos MORI, 2014). It found that practitioners were very positive about the changes, although there were anxieties about the need to retain flexibility for some cases, the added pressure on social workers under the new approach, and about delay being shifted to the pre-proceedings stage. This research took place in autumn 2013, after the publication of a series of high profile court judgments insisting on the highest standards of analysis in care proceedings (discussed further below).

\section{Prevention and preparing for court}

There are repeated calls from the judiciary, central government departments and others that local authorities must prepare cases better before bringing them to court, and that the 26 week deadline will not be achieved unless they do (e.g. Munby, 2013; Cafcass and Association of Directors of Children's Services, 2013). The President of the Family Division issued a series of newsletters in 2013-14 to promote the reforms, and in the second of them he gave detailed guidance on the local authority materials, including the social work statement (Munby, 2013). He argued that it should be much shorter than previously, focusing on analysis rather than on history and narrative. He also asserted the value of pre-proceedings work for diverting cases or saving time later, and the importance of social workers seeking early advice from the local authority lawyers.

At one level this is uncontroversial: of course cases should be well prepared, with clear plans and carefully written reports, and if they are not then the work will have to be done during proceedings; but there needs to be more recognition of the realities of working with needy and unpredictable families, and the duties on local authorities to do preventive work, not just to prepare cases for court. Furthermore, given the research findings that work done in the formal pre-proceedings stage made no difference to what happened at court, it is understandably hard for local authorities to trust that things will now be different, even if cases are thoroughly prepared. 
It appears that local authorities are being pressed to use the process more as a framework for preparing for court, rather than a late opportunity for well-supported and carefully monitored work to prevent a case going to court. This is shown, for example, in guidance on pre-proceedings practice from the Association of Directors of Children's Services (2013). This barely mentions the letter and the meeting, but in so far as it does it is late in the process of heading to court, at the 'moving to final decision' stage, not earlier on when it might still help to prevent the need for a court application. Local pre-court protocols issued by different areas in the country reflect this focus on preparation for court (e.g. Cheshire and Merseyside, 2012; Avon, North Somerset and Gloucestershire, 2013), although the Sussex protocol is a notable exception, with a clear opening statement that the aim is to bring about improvement to avoid the need for proceedings (Sussex Family Justice Board, 2013).

The demands on local authorities have been intensified by recent judgments given by the superior courts. These appear to raise the standards required of social work assessments and care plans, especially if the plan is adoption. The leading cases are $\operatorname{Re} B$ (A Child) [2013] UKSC 33; Re G (A Child) [2013] EWCA Civ 965, and Re B-S (Children) [2013] EWCA Civ 1146. In the last of those cases, at paragraph 22, the President of the Family Division, Sir James Munby, echoes the comments in the Re $B$ case, that non-consensual adoption is 'a very extreme thing, a last resort', only to be made where 'nothing else will do', 'only in exceptional circumstances'. He goes on to say that to satisfy this standard, there must be a full analysis by the local authority of all the realistically possible alternatives, with arguments for and against each (para. 34). The President heavily criticises local authorities for material that is too often 'anodyne and inadequate', insisting that 'this sloppy practice must stop' (paras. 39-40). He states that the judge must give a fully reasoned judgment, weighing up all the options (paras. 41-46), but the responsibility for furnishing the evidence is the local authority's, and at para. 49 the President holds: 
If, despite all, the court does not have the kind of evidence we have identified, and is therefore not properly equipped to decide these issues, then an adjournment must be directed, even if this takes the case over 26 weeks. Where the proposal before the court is for non-consensual adoption, the issues are too grave, the stakes for all are too high, for the outcome to be determined by rigorous adherence to an inflexible timetable and justice thereby potentially denied.

In a later case, Re S (A Child) [2014] EWCC B44 the President observed that this approach applied generally, the 26 week limit should not become a straitjacket that jeopardises justice (para. 28), but refused the mother's request for an assessment which would take the case over 26 weeks because this would 'not add significantly to what the court already knows' (para. 43).

It is worth noting that the judicial statements in $\operatorname{Re} B$ and $\operatorname{Re} B-S$ were largely if not entirely unnecessary for the decisions in the individual cases: in both cases the parents' appeals were dismissed and the authority's plan for adoption upheld. As a matter of law the statements do not set precedents. However, that being the case, the question arises as to why such senior judges should use their position in court to make them. It appears that they intended their comments to be treated as rules to be followed, giving them a power that no ordinary lecture or paper could have (see Masson, 2014).

The judgments have indeed had significant impact. Within three months, the Association of Directors of Children's Services and Cafcass issued a joint letter to directors of local authority children's services departments, in which they said that the judgments had led to some high quality assessments being sent back for further work just because they did not comply with the full checklist approach (Association of Directors of Children's Services and Cafcass, 2013). They expressed their concerns 'that a parent's right to oppose is being accorded a higher priority than a child's need for early permanence', an indication that the judgments had upset the collaborative approach to the reforms that had previously prevailed (see also Lacey, 2014). The letter called on local authorities to 
continue working to improve the quality of assessments. The two organisations subsequently issued a (non-mandatory) template for social work statements, designed to comply with the new PLO and the requirements of Re B-S (Association of Directors of Children's Services and Cafcass, 2014). (See also National Adoption Leadership Board, November 2014, para. 2, reporting a 'significant reduction in the number of placement orders and in the number of decisions made by local authorities to pursue care plans for adoption' since the Re B-S judgment.)

The message is that local authorities must sharpen up their case preparation and give the court the focused, analytic material it requires; and if the courts are not satisfied with the evidence and analysis, then local authorities, not the courts, will be to blame for proceedings lasting beyond 26 weeks. Of course, sound evidence and a thorough assessment of the viable options are essential, but even if this is provided, there will always be some parents who contest and where circumstances change during the course of proceedings. (The President's judgment in Re S gives guidance on the sort of cases that might go beyond 26 weeks, but emphasises that there must be 'solid, evidencebased reasons' for any extensions.) Such cases present two types of challenge. First, for those which are contested but without evidence of change, the challenge is whether the courts are able to abandon their culture of routinely ordering further assessments; and second, for cases which are especially complex or where circumstances do change, the courts need to be flexible and acknowledge that it is not necessarily somebody's fault if a case goes beyond 26 weeks.

\section{Conclusion}

To sum up, what do the research findings and the on-going policy and legal developments tell us about the state of relationships between the courts and local authority social work? The rhetoric is ambiguous and confusing: there are calls for all the agencies to work together to prevent children being left in abusive and neglectful situations, to speed up care proceedings, and where appropriate to place children as swiftly as possible in adoptive families; but at the same time, parents should be supported, children should be kept out of care, and adoption is the most extreme option that 
requires all other options to have been considered first. Effective interagency communication and cooperation is the key to good practice and sound decision-making, but the relationship between the courts and local authorities will always be uneasy because of their different roles in protecting the interests of children and parents. The courts are certainly not there to rubber stamp the proposals of the authority, and despite the complaints of some pressure groups the research evidence is overwhelming that they do not (e.g. Masson et al., 2008; Brophy, 2006; Cafcass, 2012). Yet it is possible for both sides to work more collaboratively without compromising their independence. This would involve judges and social work leaders sharing their different disciplinary knowledge and understandings, listening to each other without lecturing, recognising their respective contributions in non-blaming ways and agreeing on standards of practice.

Intriguingly, the drive to limit court involvement to 26 weeks has led to the courts attempting to extend their control over what happens before court. To date, there has tended to be a gulf between the pre-court and court stages, with assessments starting over again as a matter of course; now, the call is to restrict this tendency, but this must be done without undermining fairness. The courts' response to this dilemma has been to try to dictate to local authorities, in rather critical and legalistic terms, how they should use the formal pre-proceedings stage. The danger is that pre-court practice may become less about family support, more about evidence and timescales, less about prevention of proceedings and more about preparation for court.

\section{Acknowledgements}

The pre-proceedings research was funded by the Economic and Social Research Council, grant number RES-062-23-2226. The fieldwork was undertaken by Kay Bader and Julie Young, and the authors gratefully acknowledge their contribution to the study.

\section{References}


Association of Directors of Children's Services (2013) LA Pre-Proceedings Practice: Good Practice Essentials, Manchester, ADCS. Online, available at: www.adcs.org.uk/download/news/PLO-Preproceedings-practice\%20diagram.pdf

Association of Directors of Children's Services and Cafcass (2013) 'About the implications of recent Appeal Court judgments for social work case analysis in the Family Courts', Letter to Directors of Children's Services, reproduced in Family Law, 44(1), pp. 100-1.

Association of Directors of Children's Services and Cafcass (2014) Court Orders and Pre-Proceedings Guidance 2014, Manchester, ADCS. Online, available at:

http://www.adcs.org.uk/goodpractice/nsws.html

Avon, North Somerset and Gloucestershire (2013) Pre-Proceedings Protocol for Avon, North Somerset and Gloucestershire, Bristol. Reproduced in Family Law, 43(8), pp. 1068-75.

Bar Council (2012) Bar Council and FLBA Urge Care on Family Justice Reforms, London, Bar Council. Online, available at: www.barcouncil.org.uk/media-centre/news-and-pressreleases/2012/february/bar-council-and-flba-urge-care-on-family-justice-reforms/ Beckett, C., Dickens, J. and Bailey, S. (2014) Concluding Care Proceedings within 26 Weeks: Report of the Evaluation of the Tri-borough Care Proceedings Pilot, Updated Version, Norwich, Centre for Research on Children and Families, University of East Anglia. Online, available at: www.uea.ac.uk/centre-research-child-family/child-protection-and-family-support/evaluation-of-thetri-borough-care-proceedings-pilot

Booth, M. (1996) Avoiding Delay in Children Act Cases, London, Lord Chancellor's Department. Brophy, J. (2006) Research Review: Child Care Proceedings under the Children Act 1989, DCA Research Series 5/06, London, MoJ. Online, available at: 
http://webarchive.nationalarchives.gov.uk/20090117123427/http://www.dca.gov.uk/research/2006 105_2006.pdf

Brown, R. and Ward, H. (2012) Decision-Making Within a Child's Timeframe: An Overview of Current Research Evidence for Family Justice Professionals Concerning Child Development and the Impact of Maltreatment, Working Paper 16, Loughborough, Childhood Wellbeing Research Centre. Online, available at: www.education.gov.uk/publications/eOrderingDownload/CWRC-00117-2012.pdf

Cafcass (Children and Family Court Advisory and Support Service) (2012) Three Weeks in November, Three Years On: Cafcass Care Application Study, London, Cafcass. Online, available at: www.cafcass.gov.uk/media/6455/Cafcass\%20Care\%20study\%202012\%20FINAL.pdf Cafcass (2013) Care Demand Statistics, monthly update and records of previous years, available on the Cafcass website: www.cafcass.gov.uk/

Cafcass and Association of Directors of Children's Services (2013) Good Practice Guidance for Social Work Practised in the Family Courts, London, Cafcass and ADCS. Online, available at: www.adcs.org.uk/download/goodpractice/cafcass/Good\%20Practice\%20Guidance\%20for\%20social \%20work\%20practised\%20in\%20the\%20family\%20courtsv5.pdf

Cassidy, D. and Davey, S. (2011) Family Justice Children's Proceedings - Review of Public and Private Law Case Files in England and Wales, Ministry of Justice Research Summary 5/11, London, MoJ. Online, available at: www.gov.uk/government/publications/family-justice-children-s-proceedingspublic-private-law-case-files

Cheshire and Merseyside (2012) Cheshire and Merseyside Local Authority Pre-Proceedings Protocol. Online, available at: www.mfjc.co.uk/home/mfjccou1/public_ftp/resources/Local-Authority-PreProceedings-Final-for-sign-off.pdf 
Courtney, M. and Hook, J. (2012) 'Timing of exits to legal permanency from out-of-home care: the importance of systems and implications for assessing institutional accountability', Children and Youth Services Review, 34(12), pp. 2263-2272.

Davies, C. and Ward, H. (2012) Safeguarding Children Across Services: Messages from Research, London, Jessica Kingsley Publishers. Online, available at:

www.education.gov.uk/publications/eOrderingDownload/DFE-RR164.pdf

Department for Children, Schools and Families (2008) Children Act 1989, Guidance and Regulations, Volume 1, Court Orders, London, TSO. Online, available at: www.justice.gov.uk/protecting-thevulnerable/care-proceedings-reform

Department for Constitutional Affairs (2005) A Fairer Deal for Legal Aid, Cm 6591, London, TSO.

Online, available at: www.official-documents.gov.uk/document/cm65/6591/6591.pdf

Department for Education (2011) A Child-Centred System: The Government's Response to the Munro Review of Child Protection, London, DfE. Online, available at:

www.education.gov.uk/munroreview/downloads/GovernmentResponsetoMunro.pdf

Department for Education (2012) An Action Plan for Adoption: Tackling Delay, London, DfE. Online, available at: www.gov.uk/government/publications/an-action-plan-for-adoption-tackling-delay

Department for Education (2013a) Characteristics of Children in Need in England, 2012-13, Statistical First Release, London, DfE. Online, available at:

www.gov.uk/government/publications/characteristics-of-children-in-need-in-england-2012-to-2013

Department for Education (2013b) Children Looked After in England (Including Adoption and Care Leavers) Year Ending 31 March 2013, Statistical First Release, London, DfE. Online, available at www.gov.uk/government/uploads/system/uploads/attachment_data/file/244872/SFR36_2013.pdf 
Department for Education (2014a) Adoption Scorecards, January 2014, London, DfE. Online, available at: www.gov.uk/government/publications/adoption-scorecards

Department for Education (2014b) Court Orders and Pre-Proceedings for Local Authorities, London, DfE. Online, available at: https://www.gov.uk/government/publications/children-act-1989-courtorders--2

Department for Education and Skills, DCA and Welsh Assembly Government (2006) Review of the Child Care Proceedings System in England and Wales, London, DfES. Online, available at: http://webarchive.nationalarchives.gov.uk/+/http://www.dca.gov.uk/publications/reports_reviews/ childcare_ps.pdf

Dickens, J. (2006) 'Care, control and change in child care proceedings: dilemmas for social workers, managers and lawyers', Child and Family Social Work, 11: 23-32.

Dickens, J., Masson, J., Bader, K. and Young, J. (2013) 'The paradox of parental participation and legal representation in 'edge of care' meetings', Child and Family Social Work, early view.

Family Justice Review (2011a) Interim Report, London, MoJ. Online, available at: www.justice.gov.uk/about/moj/independent-reviews/family-justice-review/ Family Justice Review (2011b) Final Report, London, MoJ. Online, available at: www.justice.gov.uk/about/moj/independent-reviews/family-justice-review/ Featherstone, B., Morris, K. and White, S. (2013) 'A marriage made in hell: early intervention meets child protection', British Journal of Social Work, advance access.

HM Government (2013) Working Together to Safeguard Children: A Guide to Inter-Agency Working to Safeguard and Promote the Welfare of Children, London, DfE. Online, available at: http://media.education.gov.uk/assets/files/pdf/w/working\%20together.pdf 
House of Commons Justice Committee (2012) Pre-legislative Scrutiny of the Children and Families Bill, Fourth Report of Session 2012-13, Volume 1, HC 739, London, TSO. Online, available at: www.parliament.uk/business/committees/committees-a-z/commons-select/justicecommittee/publications/

Judiciary for England and Wales (2008) Public Law Outline - Guide to Case Management for Public Law Proceedings, London, MoJ. Online, available at: www.justice.gov.uk/guidance/protecting-thevulnerable/care-proceedings-reform.htm

Ipsos MORI (2014) Action Research to Explore the Implementation and Early Impacts of the Revised Public Law Outline (PLO), London: MoJ. Online, available at: https://www.gov.uk/government/uploads/system/uploads/attachment_data/file/304477/actionresearch-to-explore-plo-implementation-and-early-impacts.pdf

Lacey, K. (2014) 'New dilemma in adoption? A local authority view', Family Law, 44(1), pp. 89-90. Lord Chancellor's Department (2002) Scoping Study on Delay in Children Act Cases, London, LCD. Lord Chancellor's Department (2003) Protocol for Judicial Case Management in Public Law Children Act Cases, London, LCD.

Masson, J. (2014) 'The quality of care proceedings reform', Journal of Social Welfare and Family Law, 36(1), pp. 82-84.

Masson, J. and Dickens, J. (2013) 'Care proceedings reform: the future of the pre-proceedings process', Family Law, 43, pp. 1413-1420.

Masson, J. and Dickens, J. (2014) 'Protecting unborn and new babies', Child Abuse Review, early view.

Masson, J. and Dickens, J. with Bader, K. and Young, J. (2013) Partnership by Law? The PreProceedings Process for Families on the Edge of Care Proceedings, Bristol and Norwich, School of 
Law, University of Bristol and Centre for Research on Children and Families, University of East Anglia. Online, available at: www.uea.ac.uk/ssf/centre-research-child-family/research-fields/childrenprotection

Masson, J., Pearce, J. and Bader, K., with Joyner, O., Marsden, J. and Westlake, D. (2008) Care Profiling Study. London, MoJ. Online, available at: www.justice.gov.uk/publications/docs/careprofiling-study.pdf

Ministry of Justice (2014) Court Statistics Quarterly, January-March 2014, London, MoJ. Online, available at: www.gov.uk/government/collections/court-statistics-quarterly\#court-statisticsquarterly-reports

Ministry of Justice and Department for Education (2012) The Government Response to the Family Justice Review: A System with Children and Families at its Heart, Cm 8273, London, TSO. Online, available at: www.gov.uk/government/uploads/system/uploads/attachment_data/file/177097/CM8273.pdf

Munby, J. (2013) 'The revised PLO and the local authority', View from the President's Chambers (2), London, Judiciary of England and Wales. Online, available at: www.judiciary.gov.uk/publicationsand-reports/reports/family/view-from-presidents-chambers National Adoption Leadership Board (2014) Impact of Court Judgments on Adoption: What the Judgments Do and Do Not Say, London, NALB. Online, available at: http://www.adcs.org.uk/download/resources/adoption/ALB\%20-\%20Impact\%20of\%20Court\%20Jud gments\%20on\%20Adoption\%20-\%20November\%202014.pdf

Practice Direction 12A (2014) Care, Supervision and Other Part 4 Proceedings: Guide to Care Management, London, President of the Family Division. Online, available at: https://www.justice.gov.uk/protecting-the-vulnerable/care-proceedings-reform 
Sinclair, I., Baker, C., Lee, J. and Gibbs, I. (2007) The Pursuit of Permanence: A Study of the English Child Care System, London: Jessica Kingsley Publishers.

Sussex Family Justice Board (2013) Pre-Proceedings Protocol, Online, available at:

http://www.sussexfamilyjusticeboard.org.uk/pilot_documentation.html

The College of Social Work and the Family Rights Group (2013) Children and Families Bill, Joint Briefing on Clauses 1 \& 14 by the College of Social Work and Family Rights Group, London, TCSW and FRG. Online, available at:

www.tcsw.org.uk/uploadedFiles/TheCollege/_CollegeLibrary/Policy/TCSWFRGJointStatement.pdf

Welsh Assembly Government (2008) Children Act 1989, Guidance and Regulations, Volume 1, Court Orders (Wales), Cardiff, WAG. Online, available at:

wales.gov.uk/topics/health/publications/socialcare/guidance1/orders/?lang=en

Ward, H., Brown, R. and Hyde-Dryden, G. (2014) Assessing Parental Capacity to Change when Children are on the Edge of Care: an Overview of Current Research Evidence, Loughborough, Centre for Child and Family Research. Online, available at: www.gov.uk/government/publications/childrenon-the-edge-of-care-parents-ability-to-change

Wattenberg, E., Troy, K. and Beuch, A. (2011) 'Protective supervision: an inquiry into the relationship between child welfare and the court system', Children and Youth Services Review, 33(2), pp. 346-50. 